\title{
Effect of structural heterogeneity on serrated flow behavior of Zr-based metallic glass
}

\author{
L.H. Liu ${ }^{\text {a, }}{ }^{1}$, Z.Y. Liu ${ }^{\text {b, }{ }^{*}, 1}$, Y. Huan ${ }^{c}$, X.Y. Wu ${ }^{\text {b }}$, Y. Lou ${ }^{\text {b }}$, X.S. Huang ${ }^{\text {a }}$, L.J. He ${ }^{\text {d }}$, P.J. Li ${ }^{\text {a, }}{ }^{\text {** }}$, \\ L.C. Zhang ${ }^{\mathrm{e}}$ \\ a Department of Mechanical Engineering, Tsinghua University, Beijing, 100084, China \\ b Guangdong Provincial Key Laboratory of Micro/Nano Optomechatronics Engineering, College of Mechatronics and Control Engineering, Shenzhen \\ University, Shenzhen, 518060, China \\ ' State Key Laboratory of Nonlinear Mechanics, Institute of Mechanics, Chinese Academy of Sciences, Beijing, 100190, China \\ d Department of Aerospace Engineering, Tsinghua University, Beijing, 100084, China \\ e School of Engineering, Edith Cowan University, 270 Joondalup Drive, Joondalup, Perth, WA 6027, Australia
}

\section{A R T I C L E I N F O}

\section{Article history:}

Received 25 February 2018

Received in revised form

19 June 2018

Accepted 2 July 2018

Available online 5 July 2018

\section{Keywords:}

Serrated flow behavior

Structural heterogeneity

Mechanical property

Plastic deformation

\begin{abstract}
A B S T R A C T
Physical correlation between structural heterogeneity and plastic flow of metallic glasses (MGs) is crucial for the understanding of MGs' deformation mechanism. In this work, different degrees of structural heterogeneity are introduced into Zr-based MGs through different cooling rates casting. The effect of structural heterogeneity on serrated flow behavior was studied. The findings demonstrate that there exists a tendency that serration flow dynamics of the MGs transforms from a chaotic state to a selforganized critical state with increased inhomogeneity. The established correlation between structural heterogeneity and serrated flow behavior shows that the higher degree of structural heterogeneity facilitates a higher frequency of interaction and multiplication of shear bands by increasing nucleation sites, and then promotes serrated flow behavior to be more homogeneous in time and space, thereby induces transformation of dynamics behavior and improves the plasticity. The obtained results shed light on deformation mechanism of plastic flow and provide a new insight into the plasticity of MGs.
\end{abstract}

() 2018 Elsevier B.V. All rights reserved.

\section{Introduction}

As a common phenomenon in plastic deformation process, serrated flow behavior can be widely seen in many materials [1], such as crystalline materials [2,3] and amorphous alloys [4,5]. In the crystalline materials, the serrated flow behavior, called Portevin-Le Chatelier (PLC) effect [2], is regarded as resulting from the repeating dislocations pinning by solute atoms and breaking free under increasing stress $[6,7]$. In the metallic glasses (MGs), the physical origin of serrated flow behavior is supposed to different from that of crystalline material, because the MG does not possess long-rang order structure thereby is absence of the traditional defects like dislocations and grain boundaries [8-10]. Elucidating the underlying physical mechanism of the serrated flow behavior has been a

\footnotetext{
* Corresponding author.

** Corresponding author.

E-mail addresses: zyliu@szu.edu.cn (Z.Y. Liu), lipj@mail.tsinghua.edu.cn (P.J. Li).

1 These authors contributed equally to this work.
}

matter of fundamental concern for amorphous materials in the past decades [4,8,11-15]. By statistical method, it was found that serration dynamics in some MGs followed a chaotic pattern characterized as a Gaussian distribution of serration sizes [16], whilst they displayed a power-law distributed self-organized critical (SOC) state when increased the sample height-to-diameter ratio [17] or introduced in some composite crystalline phases [18]. Furthermore, the dynamics process of serrated flow behavior is revealed to be inhomogeneous in time and space $[15,19]$. The inhomogeneity is mediated by various external conditions of material, such as sample aspect ratio [20], testing temperature [19,21], strain rate used [22,23] and machine frame stiffness [24]. Up to now, however, effect mechanism of internal structure on serration flow behavior in MG is not yet fully understood.

Reminiscent of the role of dislocations in crystalline materials, search for similar "defects" in MGs has been attempted in past decades [25,26]. Recently, extensive studies have suggested that MGs are intrinsically structural heterogeneous with local configurations varying from site to site [25,27-30], manifesting some nanoscale "liquid-like" regions (i.e. flow units) with loosely packed 
atoms embedded in solid like substrate with densely packed atoms [31-33]. Both simulations and experiments have revealed that relaxation [34], yield [35,36], glass transition [32] and crystallization [37] of MGs were closely related to the structural heterogeneity or "flow unit". Although plastic deformability of MG was also reported to may be controlled by the structural heterogeneity like that of the dislocations to crystalline material $[31,33,38]$, the physical correlation between intrinsic atomic-scale structural heterogeneity and the macroscopic spatiotemporal inhomogeneous dynamics of serrated plastic flow behavior is still unclear.

As such, in this study, different degrees of heterogeneous structure in $\mathrm{Zr}$-based MGs were obtained under different cooling rates for investigating the interrelationship between structural heterogeneity and serrated flow behavior. It is found that dynamics state transforms from a chaotic state to a SOC state with increasing the structural inhomogeneity; higher degree of structural heterogeneity facilitates the serrated behavior in plastic flow and makes plastic deformation more homogeneous in time and space. Our results show that the spatially structural heterogeneity may through regulating interaction behavior of shear bands, in turn to mediate the spatiotemporal dynamics of serrated flow behavior, thereby to control the plasticity of MGs.

\section{Experimental}

$\mathrm{Zr}_{55} \mathrm{Cu}_{30} \mathrm{Ni}_{5} \mathrm{Al}_{10} \mathrm{MGs}$ with ultrahigh glass forming ability were prepared by arc melting the mixture of elemental metals with purity above $99.9 \%$ in argon atmosphere and then casting in a water-cooled copper mold. Several bulk MG samples with $3 \mathrm{~mm}$ (Sample A), $5 \mathrm{~mm}$ (Sample B), $7 \mathrm{~mm}$ (Sample C) and $9 \mathrm{~mm}$ (Sample D) respectively in diameter were fabricated directly in one time by using a stair shape mold, in order to eliminate uncertain influence of other experimental factors, such as melting temperature and smelting operation process, on the structural heterogeneity and serrated flow behavior of the MG studied. The enthalpies of MGs were measured by differential scanning calorimetry (DSC) under a purified argon atmosphere in a Parkin-Elmer DSC8000 with a heat rate of $10 \mathrm{~K} / \mathrm{min}$. The densities $\rho$ were measured by Archimedean technique, and the weights of MG samples were greater than $1 \mathrm{~g}$ to ensure higher accuracy (within $0.1 \%$ ). The free volume were obtained by using the equation [39]: $v_{f}=\left(\rho_{0}-\rho\right) / \rho$, where $\rho$ is as-casted sample, $\rho_{0}$ is the density of fully relaxed MG and it is $6.848 \mathrm{~g} / \mathrm{cm}^{3}$ for the present MG annealed at $633 \mathrm{~K}\left(\sim 0.9 \mathrm{~T}_{\mathrm{g}}\right)$ for $48 \mathrm{~h}$. The nanoscale local properties including hardness and modulus were characterized by nanoindentation on a Hysitron Ti950 system with a Berkovich-type indenter. More than 100 indentations for each sample were programed to penetrate with the same load, viz., $3000 \mu \mathrm{N}$, and the spacing between adjacent indentations was $10 \mu \mathrm{m}$. Compressive samples with the same geometrical shape ( $3 \mathrm{~mm}$ in diameter and $6 \mathrm{~mm}$ in length) were fabricated from the as-cast samples. The uniaxial-compressive tests were conducted in a MTS testing system at a strain rate of $5 \times 10^{-4} \mathrm{~s}^{-1}$. The morphologies of shear bands in fractured specimen surfaces were observed by a scanning electron microscope (SEM) (QUANTA FEG 430, FEI).

\section{Results and discussions}

Before studying the serrated flow behavior, intrinsic structures of the as-casted MGs with different diameters were investigated. Fig. 1a displays the DSC curves of $\mathrm{Zr}_{55} \mathrm{Cu}_{30} \mathrm{Ni}_{5} \mathrm{Al}_{10} \mathrm{MGs}$ from the samples with different diameters. Exothermic structural relaxation
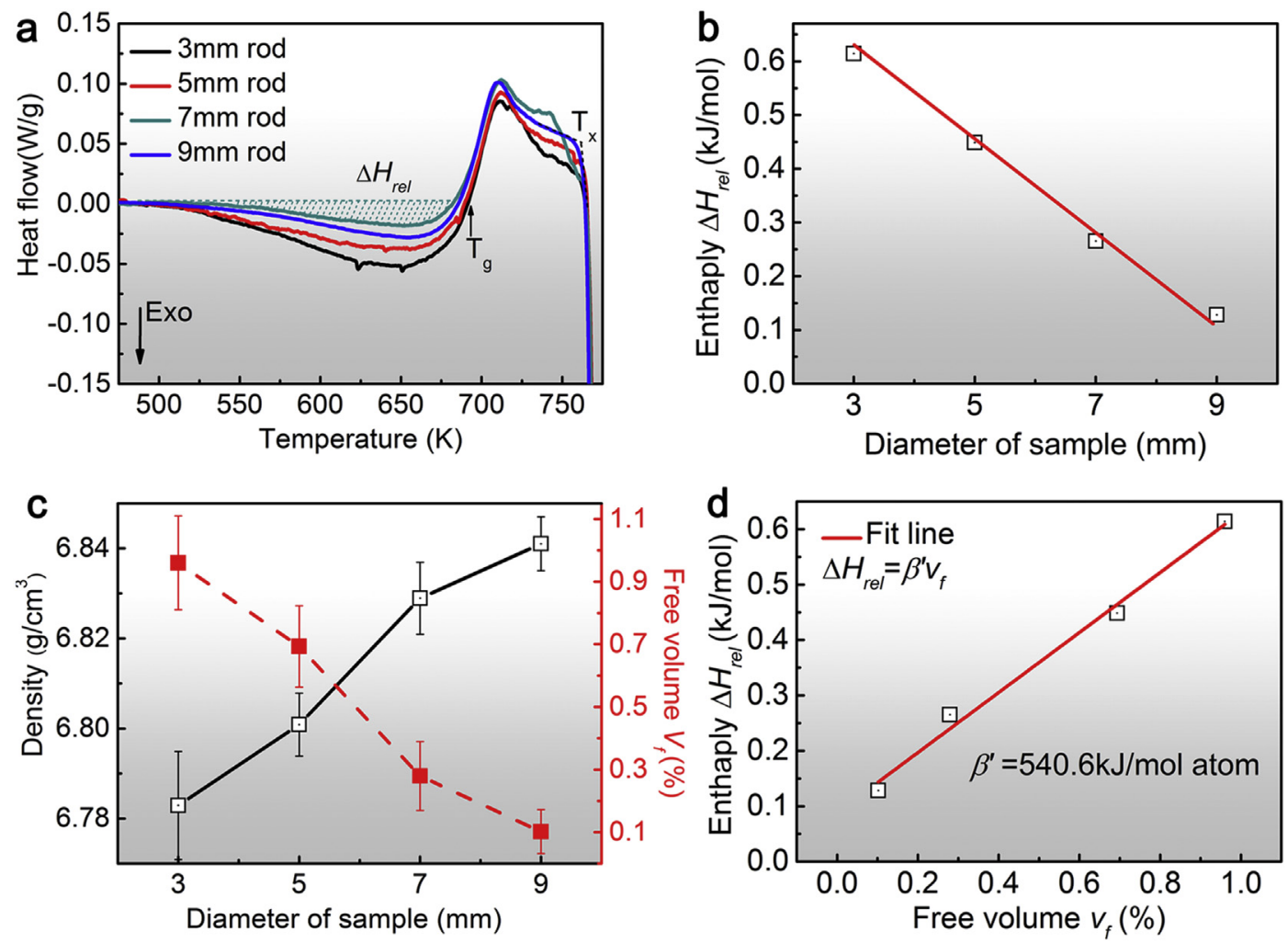

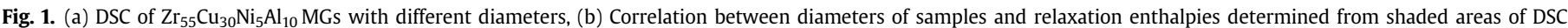

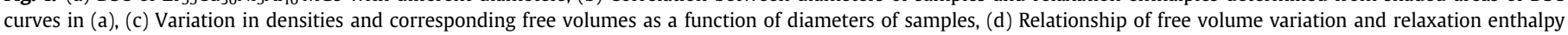
change. 
takes place in all samples when the MGs are heated towards $T_{g}$ (Fig. 1a). The relaxation enthalpies $\Delta H_{\text {rel }}$ determined by the shaded areas increase from $0.13 \mathrm{~kJ} / \mathrm{mol}$ to $0.61 \mathrm{~kJ} / \mathrm{mol}$ with decreasing the sample diameter from $9 \mathrm{~mm}$ to $3 \mathrm{~mm}$ (Table 1 ), indicating that enthalpies increase with increase of cooling rates [40,41]. Previous studies have verified that increasing relaxation enthalpy in MGs results from the increasing free volume [42-46]. The present DSC result indicates that more free volume has been introduced in MGs by a higher cooling rate. To further confirm this structure change, the free volume is quantitatively measured by monitoring density variation. Fig. 1c displays the obtained densities and corresponding free volumes as a function of the sample diameter. It is found that the relative free volume fraction with decreasing cooling rate or increasing diameter is $0.96,0.690 .28$ and $0.10 \%$, which agrees well with the trend of variation in the relaxation enthalpy (Fig. 1b). The relaxation enthalpy change vs. free volume variation is potted in Fig. 1d. Interestingly, they display a good linear relationship with a slope $\left(\beta^{\prime}\right)$ of about $540.6 \mathrm{~kJ} / \mathrm{mol} \cdot$ atom, which is quite close to value of $552 \pm 15 \mathrm{~kJ} / \mathrm{mol} \cdot$ atom as measured from the
$\mathrm{Zr}_{55} \mathrm{Cu}_{30} \mathrm{Ni}_{5} \mathrm{Al}_{10} \mathrm{MGs}$ pre-annealed at different temperatures [43].

For further studying the distribution of free volumes in different MG samples, nanoindentation is employed to characterize the local hardness and Young's modulus of the MGs fabricated under different cooling rates. The values of hardness and Young's modulus which were obtained by fitting the nanoindentation curves are displayed in Table 1. An increasing average nano-hardness and Young's modulus with increasing sample diameter are observed, which further confirm that a looser structure was frozen in MGs with higher cooling rate [47-49]. The reduced hardness $h_{r i}$ is determined as $h_{r i}=h_{i} / H,\left(H=(1 / n) \Sigma_{i} h_{i}, h_{i}\right.$ is $i$ th nano-hardness value) to compare the nano-hardness distributions among the four MGs. The distributions of the reduced nano-hardness are displayed in Fig. 2 and fitted by Gaussian function. The fitting parameter $R$ is $0.92,0.88,0.87$ and 0.94 for samples A, B, C and D, respectively. It indicates that all the dates are well fitted. It is clearly showed that the MG fabricated under higher cooling rate has a wider distribution of hardness than its counterparts with less (Fig. 2), manifesting as the FWHM of fitted line decreases from

Table 1

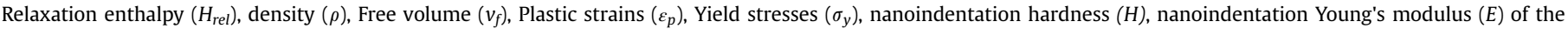
$\mathrm{Zr}_{55} \mathrm{Cu}_{30} \mathrm{Ni}_{5} \mathrm{Al}_{10} \mathrm{MGs}$.

\begin{tabular}{|c|c|c|c|c|c|c|c|}
\hline Sample & $H_{r e l}(\mathrm{~kJ} / \mathrm{mol})$ & $P\left(\mathrm{~g} / \mathrm{cm}^{3}\right)$ & $v_{f}(\%)$ & $\sigma_{y}(\mathrm{MPa})$ & $\varepsilon_{p}(\%)$ & $H(\mathrm{GPa})$ & $E(\mathrm{GPa})$ \\
\hline A & 0.61 & $6.783 \pm 0.012$ & $0.96 \pm 0.15$ & $1642 \pm 25$ & $11.56 \pm 2.1$ & $4.98 \pm 0.41$ & $99.2 \pm 3.9$ \\
\hline B & 0.46 & $6.801 \pm 0.007$ & $0.69 \pm 0.13$ & $1666 \pm 35$ & $3.26 \pm 1.1$ & $5.04 \pm 0.31$ & $100.5 \pm 3.4$ \\
\hline $\mathrm{C}$ & 0.27 & $6.829 \pm 0.008$ & $0.28 \pm 0.11$ & $1742 \pm 26$ & $0.98 \pm 0.3$ & $5.18 \pm 0.31$ & $103.7 \pm 3.4$ \\
\hline $\mathrm{D}$ & 0.13 & $6.841 \pm 0.006$ & $0.10 \pm 0.07$ & $1745 \pm 30$ & $0 \pm 0.1$ & $5.20 \pm 0.20$ & $103.8 \pm 3.2$ \\
\hline
\end{tabular}
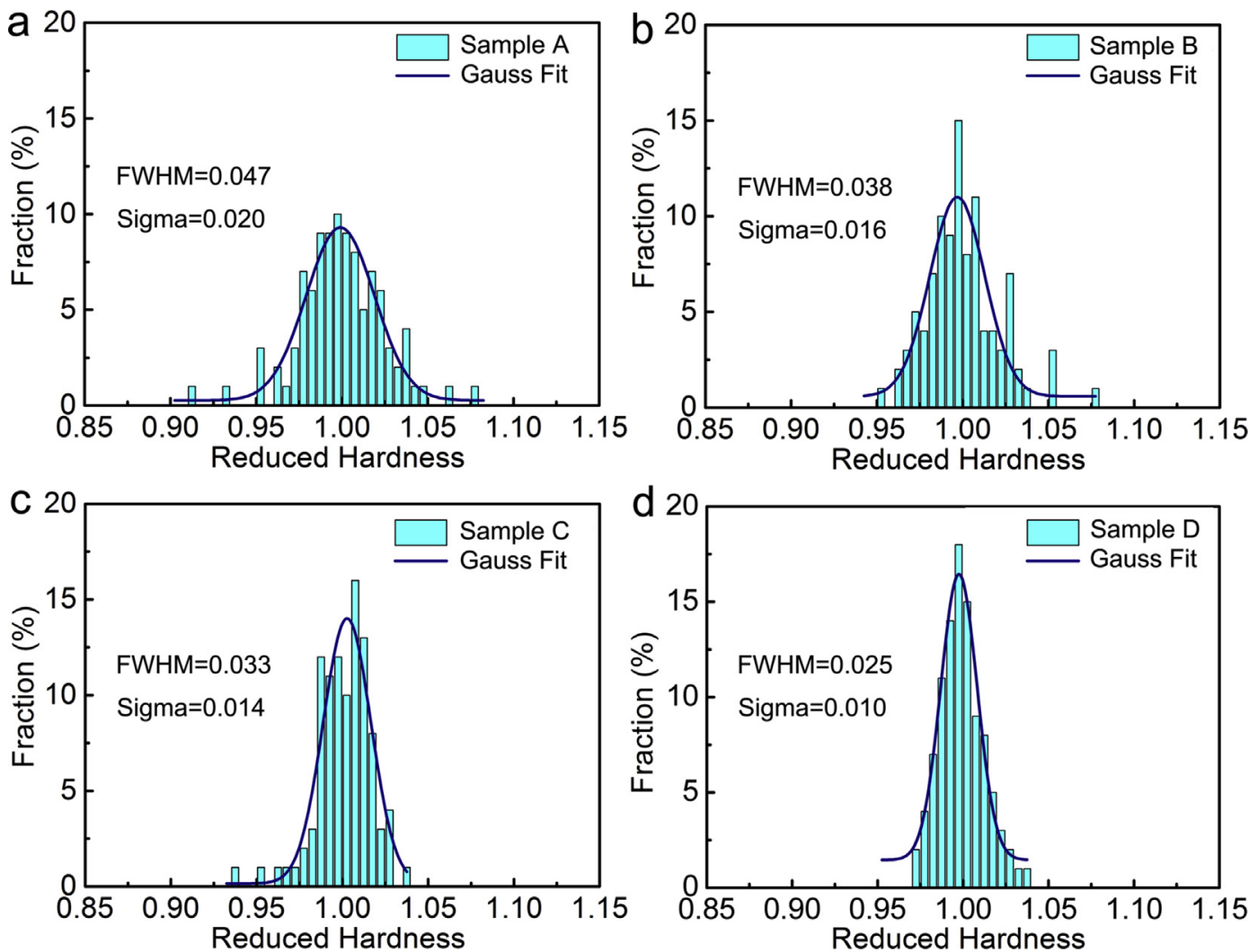

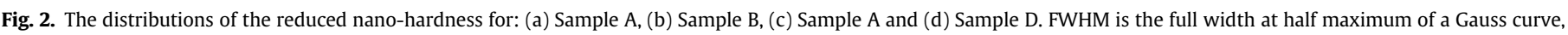
Sigma is standard deviation in Gaussian function. 
0.047 to 0.025 , and standard deviation decreases from 0.020 to 0.010 with increased in sample diameters. Wang et al. [25] pointed out that the regions with more free volume possessed "liquid-like" property such as low hardness and modulus, namely "flow unit". The larger nano-hardness suggests that there locally exist the more free volumes at where the indentation experiment is conducted. The wider distributions of nano-hardness in present MGs indicates that higher degree of structural heterogeneity or more flow units has been introduced in present MG by higher cooling rate, which has been confirmed in previous researches [32,50,51].

Afterwards, compressive tests of $\mathrm{Zr}_{55} \mathrm{Cu}_{30} \mathrm{Ni}_{5} \mathrm{Al}_{10} \mathrm{MGs}$ with different degree of structural heterogeneity were conducted to study the effect of internal structure on serrated flow behavior. The results show that there exists a brittle-to-ductile transition for the MGs with increasing the structure inhomogeneity (Fig. 3a). The samples with higher degree of structural heterogeneity display a larger plasticity. The corresponding plastic strain for the sample A, $B$ and $C$ and $D$ is $11.56,3.26,0.98 \%$ and $0.0 \%$ respectively (Fig. 3a and Table 1). Sample D with the least structural inhomogeneity displays a brittle fracture behavior; little plastic strain is observed on its stress-strain curve (Fig. 3a). As such, only the samples A, B and C are further used in the following study of the correlation between mechanical properties and structure inhomogeneity. The detailed
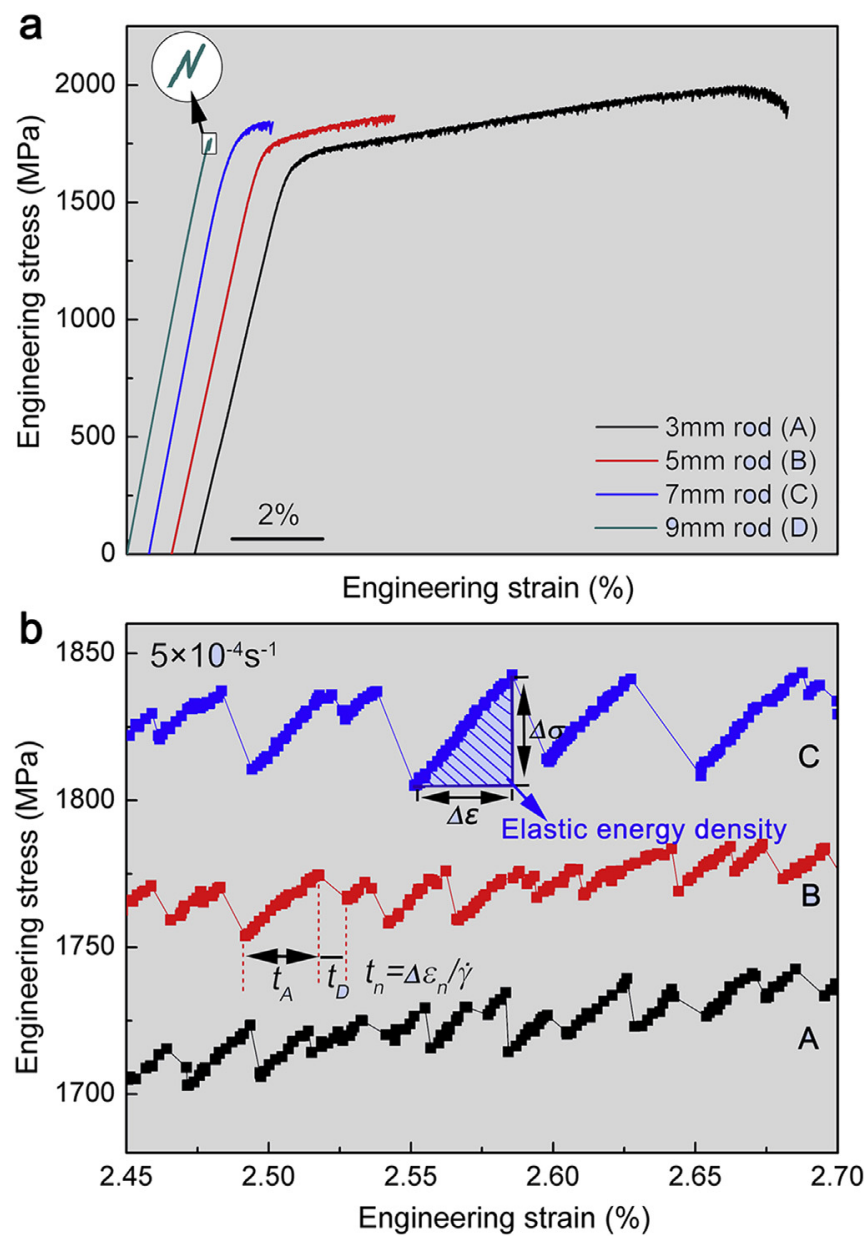

Fig. 3. Stress response of $\mathrm{Zr}_{55} \mathrm{Cu}_{30} \mathrm{Ni}_{5} \mathrm{Al}_{10} \mathrm{MGs}$ : (a) compressive engineering stressstrain curves of MGs with different degree of structural heterogeneity, (b) serrated flow behavior of samples A, B, and C, respectively. The shaded area is elastic energy density for one serration event. $\Delta \varepsilon_{E}$ and $\Delta \sigma_{E}$ are the elastic stress and elastic strain in one serration, respectively; $\Delta \sigma_{D}$ is stress drop; $t_{A}$ and $t_{D}$ is the stress ascending time and the stress drop time, respectively. serration behaviors are investigated by magnifying the stress-strain curves. All the investigated samples after yielding at about $1.73 \%$ elastic strain exhibit an intermittent flow, displaying as repeated cycles of stress loading followed by stress drops (Fig. 3b). It is found that the average serration sizes of MGs decrease with increasing inhomogeneity of spatial structure as shown in Fig. 3b. As the strain rate used in compression testing was the same for all samples in this work, the smaller serration size indicates that the higher degree of structural heterogeneity in MGs facilitates serrated flow behavior to be more homogeneous in time.

Since the stress drop is proportional to serration size, the magnitude of stress drops $\left(\Delta \sigma_{D}\right)$ were extracted from stress-strain curves and these data were statistically analyzed to study the serration flow dynamics behavior with variation in structural inhomogeneity [52]. Serrations with amplitude less than $1 \mathrm{MPa}$, which most result from machine noise, were not taken into account in the statistical analyses [13]. The statistic serration sizes for samples with decreasing structural heterogeneity are shown in Fig. 4a-c. As can be seen, many small serrations are evident in MG sample A; by contrast, fewer small serrations are observed for sample in B and C. Interestingly, the maximum stress drop magnitude are located at very narrow window of about 47.1 MPa-52.5 MPa (Fig. $4 \mathrm{a}-\mathrm{c}$ ), which are quite close to the predicted maximum stress drop value (about $55 \mathrm{MPa}$ ) by the model proposed by Qiao et al. [53], indicating that the maximum stress drop magnitude is insensitivity to internal structure. Furthermore, it can be found that the serration sizes generally increase linearly with increasing the strain until fracture (Fig. $4 a-c)$. The increasing rate of serration size $\left(\Delta \sigma_{\max } / \Delta \varepsilon\right)$ varies with the degree of structural heterogeneity and it is determined to be $3.2 \mathrm{MPa} / \%, 8.1 \mathrm{MPa} / \%$, and $16.2 \mathrm{MPa} / \%$ for sample A, B and C, respectively. Previous study has shown that increasing rate of serration size $\left(\Delta \sigma_{\max } / \Delta \varepsilon\right)$ varied with compositions [52]. For example, the Fe-based MG always displays a large $\Delta \sigma_{\max } / \Delta \varepsilon$ of $40 \mathrm{MPa} / \%$, while the Pa-based MG displays much smaller rate of $13 \mathrm{MPa} / \%$ [52]. Nevertheless, the present obtained results indicate that variation of $\Delta \sigma_{\max } / \Delta \varepsilon$ may intrinsically arise from the structural variation.

To further reveal the underlying deformation mechanism, the distribution of the number of serrations at different serration sizes for the samples A-C is shown in Fig. $4 \mathrm{~d}-\mathrm{f}$, respectively. The distribution of stress drops displays a monotonically decreasing trend for the sample A with the highest degree of structural heterogeneity (Fig. 4d). A cumulative probability distribution, i.e. the percentage of the number of serration events with the stress drops being larger than a certain value, $\mathrm{P}(>\mathrm{s})$, is calculated and plotted in Fig. $4 \mathrm{~d}$ inset. As can be seen, $\mathrm{P}(>\mathrm{S})$ is well fitted by a power-law distribution with a squared exponential decay function $[13,54]$ :

$P(>s)=A s^{-\beta} \exp \left[-\left(s / s_{C}\right)^{2}\right]$

where $A$ is a normalized constant of 1.49 herein, $\beta$ is the scaling exponent with a fitting value of 0.37 and $s_{c}$ is the cut-off stress drop magnitude fitted by $20.9 \mathrm{MPa}$. The fitted equation (1) indicates that the distribution of the stress drops is essentially a power-law relation up to stress drops at $20.9 \mathrm{MPa}$, after which the exponential decay factor plays a dominant role. Usually, the power-law relation is an indicator of the self-organized critical (SOC) state in serration dynamics of MGs [54]. Interestingly, for sample C with the relative less structural heterogeneity, most the stress drop values fall in the range of $8-15 \mathrm{MPa}$ and the distribution histogram displays a peak shape. The distribution can be well fitted by the Gaussian function (Fig. 4f). In general, Gaussian-like distribution is the typical feature of a chaotic dynamic state of serrated flow behavior, which has been reported in some crystalline materials 

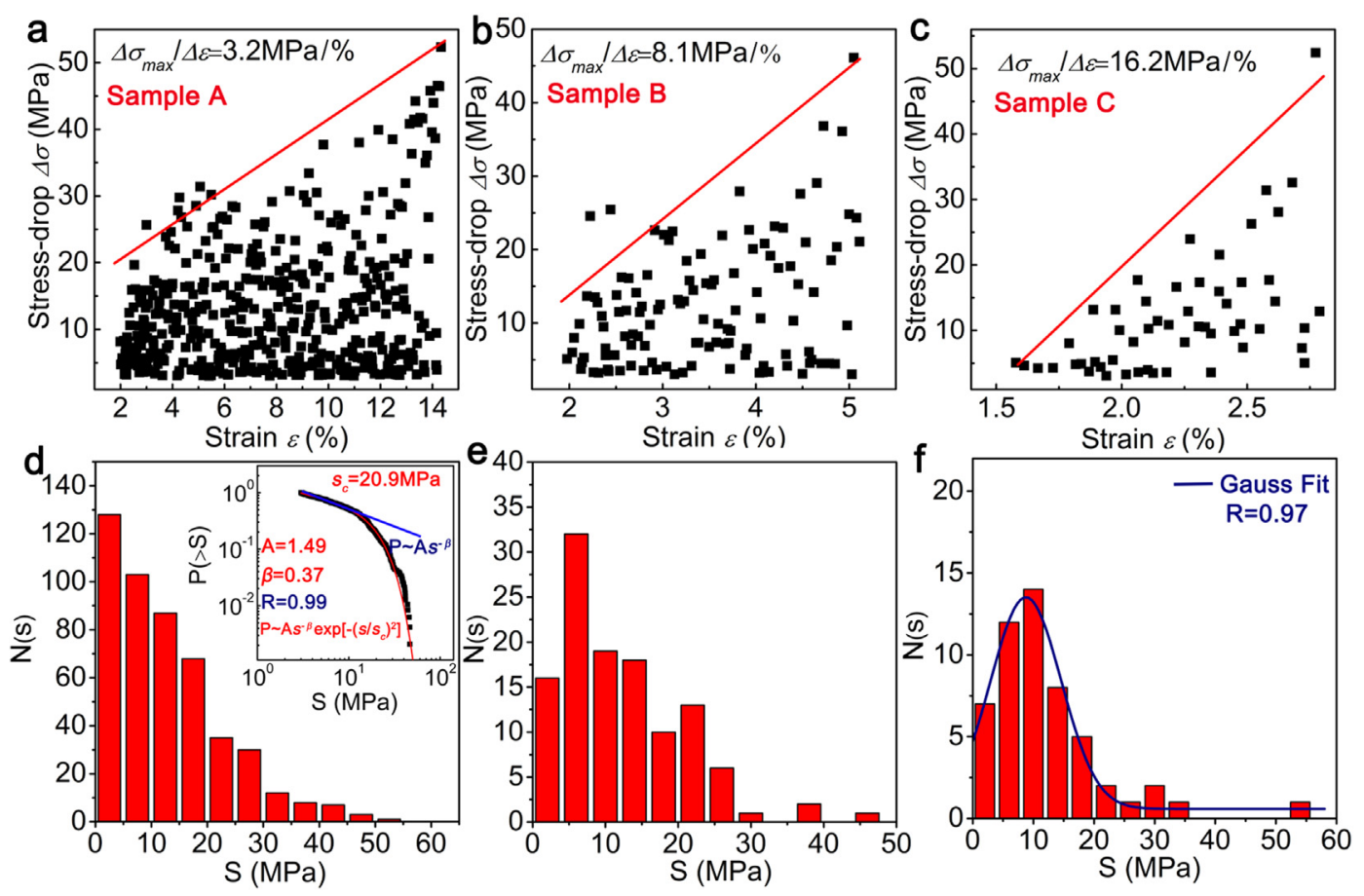

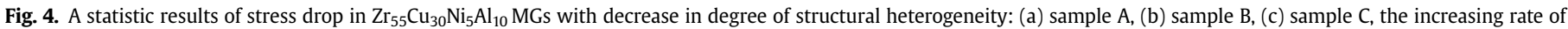

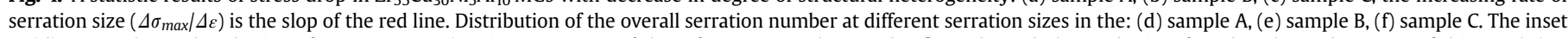
in (d) is cumulative distribution of serration size. (For interpretation of the references to colour in this figure legend, the reader is referred to the Web version of this article.)

[55], MG matrix composite [18] and MGs with large sample heightdiameter ratio [17]. The serrations dynamic behavior transforms from a SOC state into a chaotic state with the decrease in structural heterogeneity, corresponding to the change in deformation mechanism from ductile to brittle behavior, indicating that inhomogeneity of internal structure plays a critical role in the dynamic behavior of plastic deformation of the MGs. The detail mechanism is studied and will be discussed in the following.

It is known that individual serration event consists of stress ascending and drop, corresponding accumulation and release of elastic energy (Fig. 3b) [56]. The storage elastic energy densities of serration events for the MGs are calculated and displayed in Fig. 5a (only the data from sample A is shown here). Similar to the previous report [13], a rising trend of storage elastic energy densities can be observed with increasing strain (Fig. 5a). The maximum elastic energy density of the $\mathrm{Zr}_{55} \mathrm{Cu}_{30} \mathrm{Ni}_{5} \mathrm{Al}_{10} \mathrm{MGs}$ is determined to be 7230,9150 and $9843 \mathrm{~J} / \mathrm{m}^{3}$ (thus the corresponding energy is about $3.19 \times 10^{-4}, 4.04 \times 10^{-4}$ and $4.35 \times 10^{-4} \mathrm{~J}$ respectively) for sample $\mathrm{A}, \mathrm{B}$ and $\mathrm{C}$, respectively. The average elastic energy density displays an increasing trend with decreasing the degree of structural heterogeneity is 1681,2318 and $3214 \mathrm{~J} / \mathrm{m}^{3}$, respectively (Fig. $5 \mathrm{~b}$ ).

According to shear transformation model of MGs, the formation of shear band could be considered as configurationally hopping of deformation units (i.e. flow unit herein) $[13,25]$. The formation energy of a shear band $E_{S}$ can be estimated by equation: $E_{S}=N \times W$, where $N$ is the number of activated deformation unit in shear layer and $W$ is the activation energy of the individual deformation unit. It was reported that the activation energy for the deformation unit hopping follows the equation [57]: $W=\left(8 / \pi^{2}\right) \xi G \gamma_{C} \Omega$, where $\xi \approx 3$ is a correction factor arising from the matrix confinement of a "dressed" deformation zone, $\gamma_{C} \approx 0.027$ is the yield strain limit, $G$ is shear modulus and the values of $G$ is $31 \mathrm{GPa}$ measured by torsional test [58], and the effective transformation volume, $\Omega$, is $4.1 \mathrm{~nm}^{3}$ according to the results measured by a dynamic mechanical analyses on various $\mathrm{Zr}$-based MGs [57]. As such, the activation barrier for one deformation unit is estimated to be $8.3 \times 10^{-18} \mathrm{~J}$. As shear band slips along shear plane with the inclined angle of about $45^{\circ}$, the shear plan area (A) is approximately $9.9 \times 10^{-6} \mathrm{~m}^{2}$, and the thickness of shear band is assumed to be approximately $20 \mathrm{~nm}$ [59], hence, the volume of one shear band fully crossing the shear plane of the MGs is determined to be about $1.98 \times 10^{14} \mathrm{~nm}^{3}$, thus the number of deformation units in shear layer is $4.83 \times 10^{13}$. According to the above-mentioned model $[13,25]$, therefore, theoretically it should take energy of about $4.01 \times 10^{-4} \mathrm{~J}$ to induce a fully crossed shear band. It is interesting to found that the value is approximately equal to that of maximum elastic energy of serrations near fracture strain $\left(3.19 \times 10^{-4} \sim 4.35 \times 10^{-4} \mathrm{~J}\right)$. The result indicates that the maximum elastic energy of serrations is mainly used to activate a shear band that generated at near fracture strain. In addition, the average elastic energy density decrease for sample C, B and A (Fig. 5b), indicating higher degree of structural heterogeneity promotes the shear bands to be activated easier.

It is showed that the accumulated serration elastic energy would be released, when it ascended to a large enough value which can activate a shear band, thereby lead to once slipping of shear band in a localized deformation layer, accompanying with a stress drop (Fig. 6a). Song et al. [60] pointed out that shear band viscosity (i.e. viscosity of localized deformation layer) of MG during stress release could be calculated using the following equation:

$\eta=\frac{(P / A) \cos \theta \sin \theta}{(\Delta L / \cos \theta) / t_{\mathrm{D}} d}$

where $P$ is the load on the sample, $A$ is the cross-section area of the 

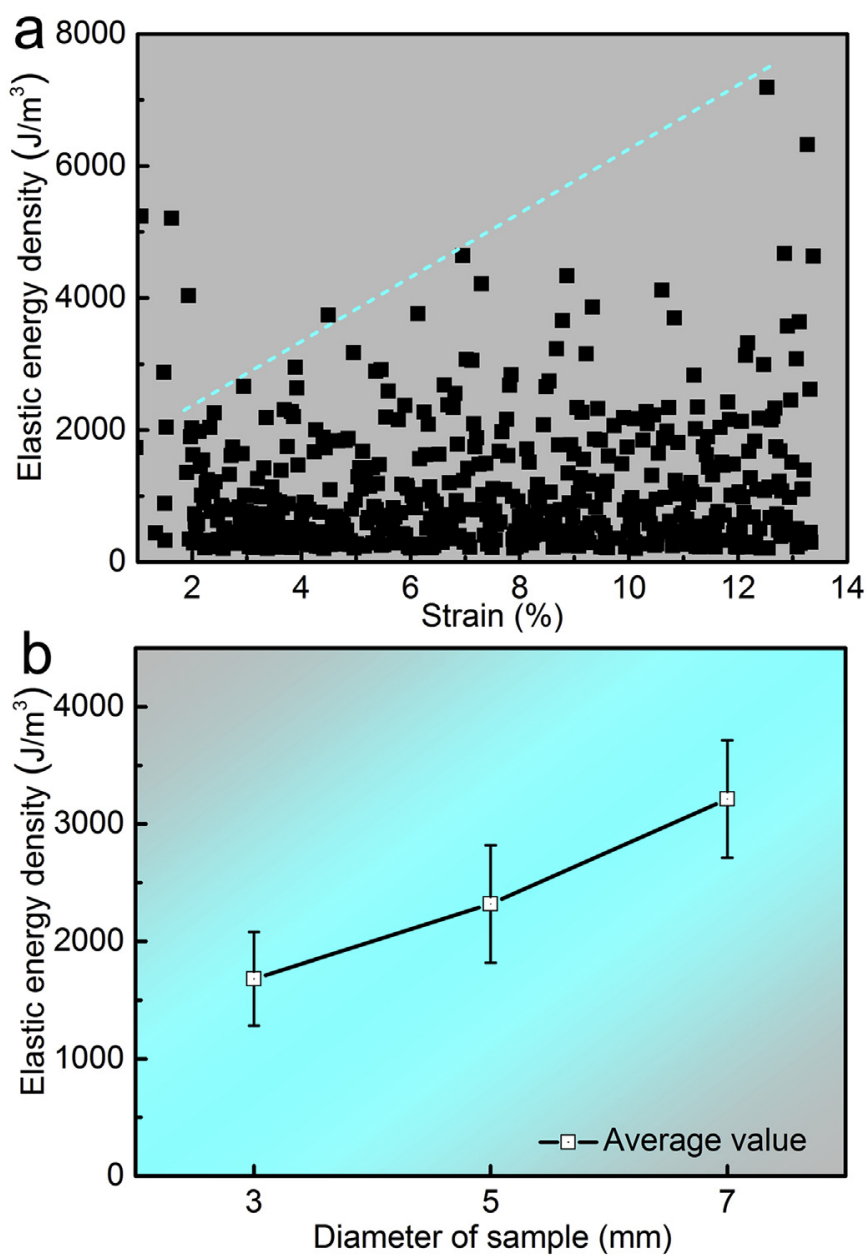

Fig. 5. (a) Elastic energy density distribution along the strains for the sample A, the dashed line represents the tendency of elastic energy density; The dotted line denotes the boundary of elastic energy density distribution; (b) Average elastic energy density of sample with decrease in degree of structural heterogeneity or increasing sample diameter.

sample, $\theta$ is the shear angle, and $\Delta L$ and $t_{D}$ are size of the displacement burst and elapsed time of displacement, respectively, and $d$ is the thickness of shear band. Base on equation (2), the calculated shear band viscosities for the different spatially structural MGs are shown in Fig. 6b-d. It found that the viscosities display a decreasing tendency with increasing strain, while the decline rate for sample $C$ is far faster than that for sample A (Fig. $6 \mathrm{~b}-\mathrm{d}$ ). This variation tendency is the same with that of the increasing rate of serration size $\left(\Delta \sigma_{\max } / \Delta \varepsilon\right)$ to the internal structural change. Furthermore, it is showed that most of the shear band viscosities for present samples are smaller than $1.0 \times 10^{7} \mathrm{~Pa} \mathrm{~s}$, which are in a very similar range as the viscosity value commonly measured from $\mathrm{Zr}_{64.13} \mathrm{Cu}_{15.75} \mathrm{Ni}_{10.12} \mathrm{Al}_{10} \mathrm{MG}$ deformed at strain rates of $2 \times 10^{-4} \mathrm{~s}^{-1}$ [60]. Regardless of the degree of structural heterogeneity, it is interesting to find that all MGs at fracture strain display the same minimum viscosity of $1.1 \times 10^{4} \mathrm{~Pa}$ s, which is equal to that for the $\mathrm{Zr}_{64.13} \mathrm{Cu}_{15.75} \mathrm{Ni}_{10.12} \mathrm{Al}_{10} \mathrm{MG}$ [60] and is very close to the minimum value of $2 \times 10^{4} \mathrm{~Pa}$ s for the Vitreloy $1 \mathrm{MG}[60,61]$. It indicates that the minimum viscosity is similar to that of maximum stress drop magnitude, is independent of the internal structure [53]; the maximum stress drop value and the minimum viscosity possible could be a criterion of fracture for MGs [64]. The measured viscosities of shear bands $\left(1.1 \times 10^{4}-3.9 \times 10^{7} \mathrm{~Pa} s\right)$ in this work are several orders in magnitude less than the viscosity of MG at glass transition temperature $\left(10^{12} \mathrm{~Pa} \mathrm{~s}\right)$, indicating that glass transition has already occurred in the shear layers [65].

With regard to the amorphous alloys, generally it was considered as homogeneous solid, i.e. the excess volume is evenly distributed in the material. However, extensive studies [25] have suggested that metallic glass are intrinsically structural heterogeneous, i.e. existing heterogeneity, manifesting there are some nanoscale "liquid-like" regions (i.e. flow units) with loosely packed atoms embedded in solid like substrate with densely packed atoms [26-28]. On the basis of the above findings and our previous study results [35,36], a possible relationship between structural heterogeneity and formation mechanism of shear band is established to elaborate structural effects on serrated flow behavior [66]. As illustrated in Fig. $7 \mathrm{a}-\mathrm{c}$, forming a shear band or a serration event would undergo several stages: Before loading, the flow units are frozen in as-casted MGs, causing an inhomogeneous structure [25]. As the pressure is gradually loaded, the sample would firstly step into elastic deformation stage with increasing energy of system. Because of structural heterogeneity, the distribution of the energy and stress in system becomes inhomogeneous [62]. Stress concentration is induced due to modulus difference between the flow units and matrix [13], which makes a higher local stress than the applied stress [63]. Afterwards, the atomic local motions in flow unit are activated in priority, causing a time-dependent reversible anelastic deformation of MGs (Fig. 7a) [34,50]. With further increase of pressure, the liquid-like cores would gradually begin to configurationally hop or grow by agglomeration and penetration of flow units (Fig. 7b) [35]. This stage corresponds to a linear accumulation of energy in a serration of the stress-strain curve (Fig. 3b). Up to a critical point of the energy storage, i.e. the highest stress values in a serration, penetrating flow units would form a supercooled liquid layer (Fig. 7c), displaying as a low viscosity of $10^{4} \sim 10^{6} \mathrm{~Pa} s$ which is lower that of MGs at their glass transition temperature (Fig. 6). Once the viscous layer is formed (Fig. 7c), the entire structure in the shear plane becomes immediately instability, thus the soft liquid-like layer proceeds viscously by sliding along the shear plane, with elastic energy dissipation under shear strain rate ranging from $10^{3} \sim 10^{8} \mathrm{~s}^{-1}$ (Fig. 6), accompanied by a stress drop in serration pattern. After serration elastic energy has been dissipated, the internal structure of the liquid-like layer begins to recover and reconstruct the solid-like matrix [35], thus the shear band is fully arrested. Further increasing load, the sample would store additional energy again to induce another serration or shear band. In the end, the plastic strain reaches a critical value, where the shear band loses its ability to recover and cannot sustain more plastic deformation, resulting in catastrophic fracture along the shear plane.

Upper part result reveals theoretically it takes energy of about $4.01 \times 10^{-4} \mathrm{~J}$ to induce a fully crossed shear band, but experimentally the most storage elastic energies of the serration events are less than the theoretical value (Fig. 5a). Besides, it is found that the serration size increases gradually with strain (Figs. $4 a-c$ and $5 a$ ), and the increasing rate $\left(\Delta \sigma_{\max } / \Delta \varepsilon\right)$ rises sharply with decreasing degree of structural heterogeneity (Fig. $4 a-c$ ). These can be explained as per the above discussions. Flow units played the role as nucleation sites for shear band during plastic deformation. The serration elastic-energy storage in the reloading stage is mainly used to overcome energy barrier for penetration or configurationally hopping of flow units to form a viscous shear layer. Actually, the 

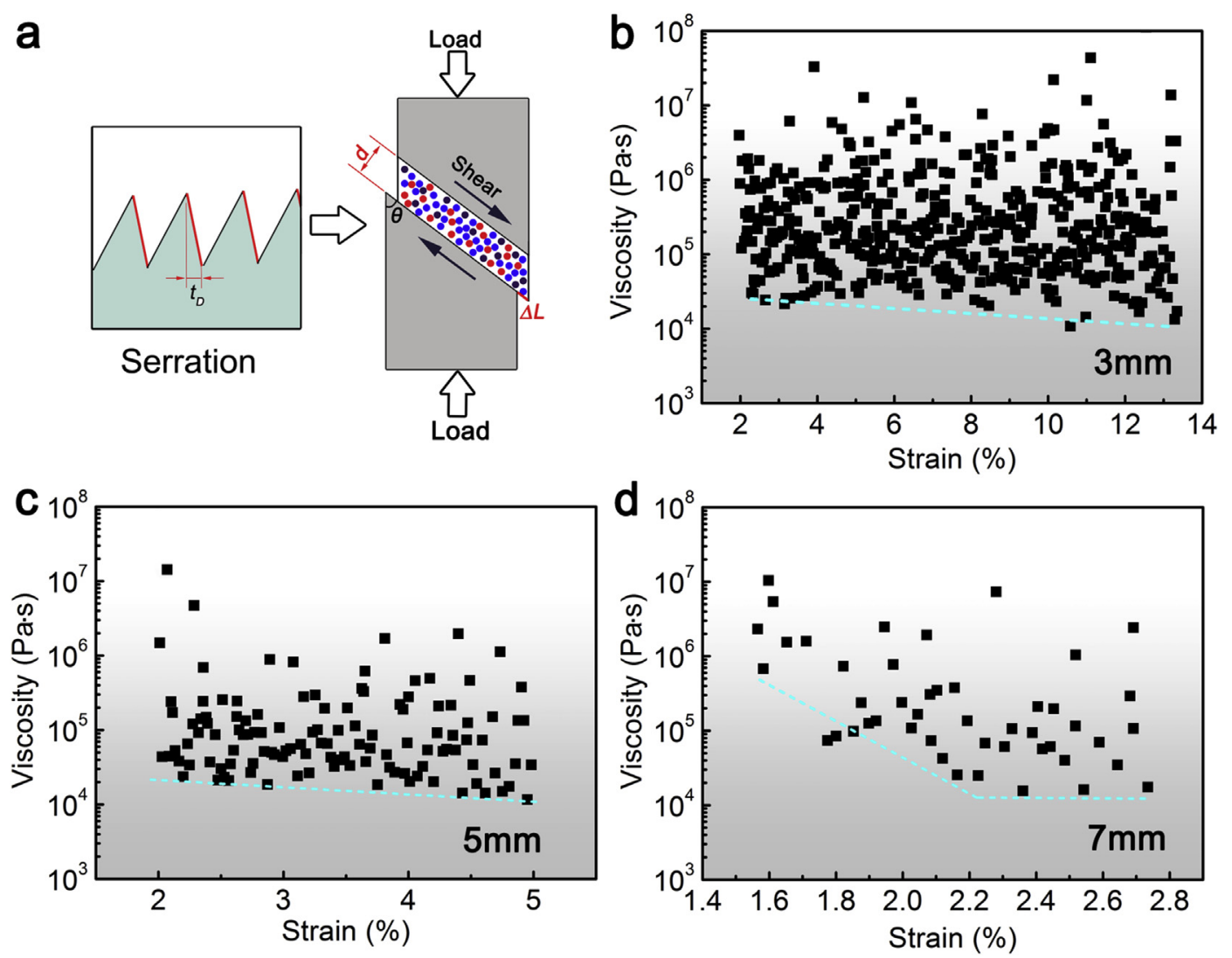

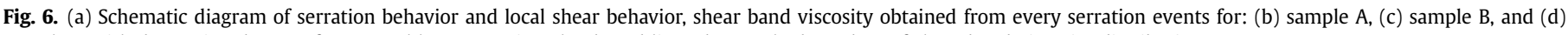
sample $\mathrm{C}$ with decreasing degree of structural heterogeneity. The dotted lines denote the boundary of shear band viscosity distribution.

formation energy of a shear band is not a constant. On the one hand, there exist lots of partial shear events during serrated flow process. These partial shear bands, which cannot fully shear across the cross-section of the specimen, are need less energy to be activated [13], which have been experimentally observed in previous works $[13,66,67]$; On the other hand, effective transformation volume $\Omega$ or size of flow units in shear region is a changed value, i.e. energy barrier for configurationally hopping of flow units is not a constant, evidenced by the distribution of nano-hardness in present study (Fig. 2). Experimentally, Jiao et al. [68] pointed out that distribution of energy barriers of flow units is close to a Gaussian distribution. During plastic deformation process, therefore, shear band would be initiated primarily at the flow unit sites with smaller energy barriers, and leads to small stress-drop after the energy dissipation. After exhaustion of the fragile flow sites, higher activation energy is needed to activate tough flow units to form new shear band manifesting as lager serration event. Therefore, increase in serration size with strain is observed during the serration flow process (Fig. $4 \mathrm{a}-\mathrm{c}$ ). With increasing degree of structural heterogeneity, more free volumes are frozen in a MG, thus the distribution of the flow units is evener or wider according to the nanoindentation tests (Fig. 2). Therefore, the activation energy barrier difference between two flow units decreases. Consequently, the initiation of a new shear bands becomes easier and initiation frequency becomes larger, manifested as more homogeneous plastic deformation in time (Fig. 3b). As a result, the increasing rate of serration size $\left(\Delta \sigma_{\max } / \Delta \varepsilon\right)$ with increasing degree of structural heterogeneity turns into smaller (as shown in Fig. $4 a-c$ ).

Serration dynamics changes from SOC state to chaotic state was observed in the MGs with decreasing degree of structural heterogeneity (Fig. 4d-f), along with a deformation mechanism transition from ductile to brittle. In physics, SOC state is a property of dynamical systems, in which their macroscopic behavior displays the spatial and/or temporal scale-invariance characteristic [2,54]. As the self-organized critical system can tune effectively itself as it evolves towards criticality, system with SOC behavior can buffer larger disturbance by dissipating external effect through cooperative motion of connected participants. In contrast, chaotic state is dynamical systems that are highly sensitive to initial conditions, in which any small perturbation would set off a cascading pattern, which would make the system deviate from its original trajectory, thus inclined to generate accidental events. As above discussed, during plastic deformation, it is certain that the activation of shear band become more and more difficult with growing strain due to Gaussian-distributed energy barriers of flow units [68], while the moving direction of next shear band is random. If the propagation direction of newly formed shear band is different from the former one, they would generate shear band intersection (Fig. 7d) thereby induce secondary or multiple shear bands, causing one or a succession of small serrations. With increasing degree of structural heterogeneity, the nucleation sites of shear band increases gradually. Therefore, the interaction and multiplication of shear bands would become more distinct (Fig. 7d-f), thus more small serrations would be observed. It was reported that the interaction-induced small serration events would push the system to a SOC state [13], which can stand up to more accidents thus delay fracture of the MGs. Conversely, if there is a small amount of nucleation sites of shear band in MG, deformation would occur along a primary shear plane with fewer intersections (Fig. 7d). As such, only a few smallsized serrations could be observed (Fig. 4c). External disturbance 

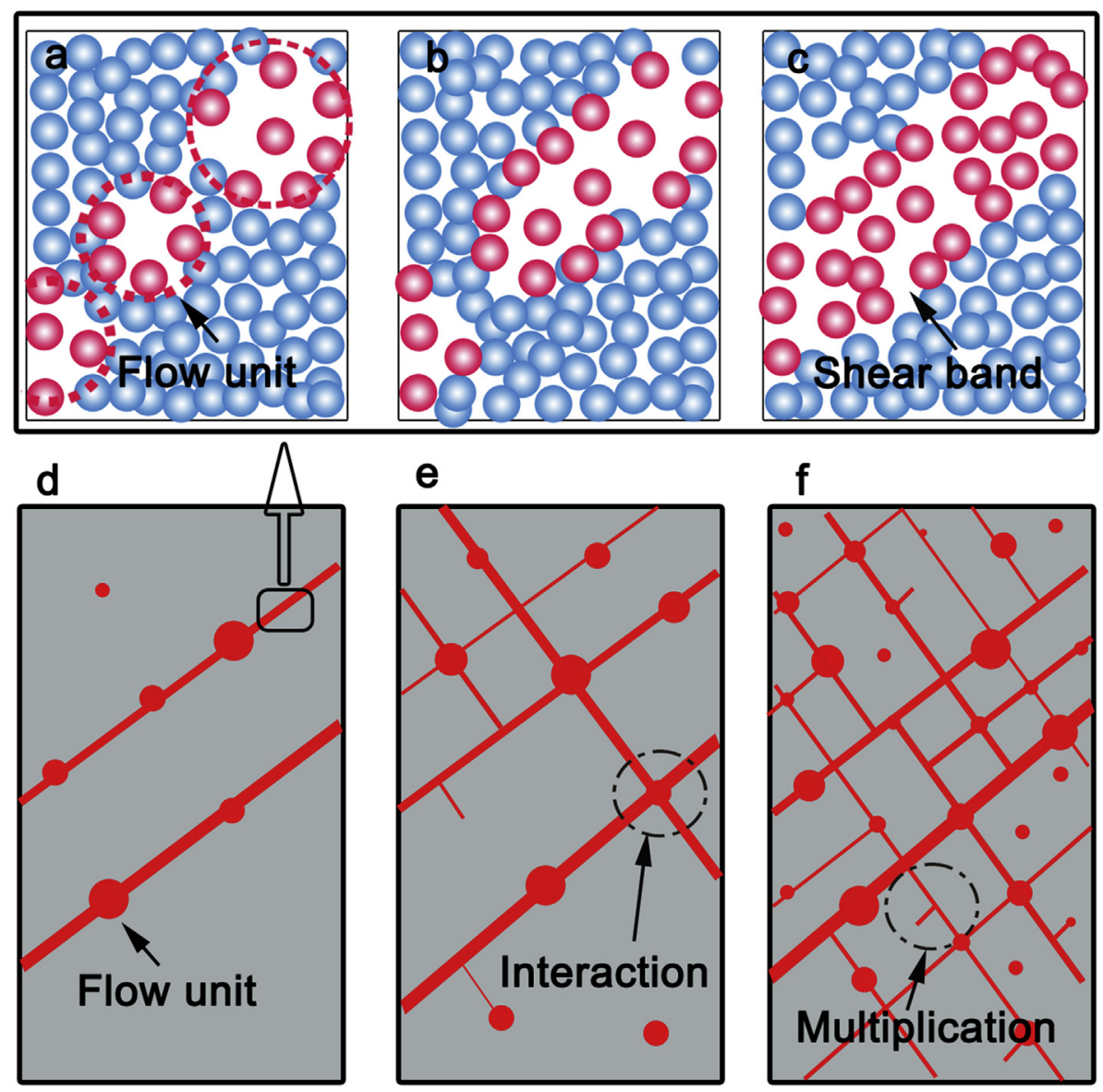

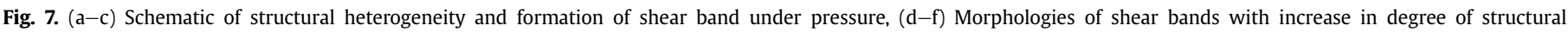
heterogeneity.

effect cannot be dissipated through cooperated motion of connected participants, i.e. shear bands. The system dynamics changes to a chaotic state, resulting in unexpected brittle fracture.

To verify this hypothesis, SEM photographs of surfaces for samples with different serrated flow dynamics state are shown in Fig. 8. For the sample $\mathrm{C}$ with chaotic dynamic state, the shear bands distribute paralleled on the surface of sample, and few secondary shear bands and interaction of shear bands can be observed (Fig. 8a). With increasing degree of structural heterogeneity, serrated flow dynamics of sample A transforms into a selforganized critical state. It is found that the density of shear bands is far higher than that of sample with less flow units; profuse of secondary shear band and interaction of shear bands are obviously presented in Fig. 8b. In view of the shear-banding operations, the more amount and smaller sized shear bands are observed in the MGs with more flow units (Fig. 8b), indicating that higher degree of spatially structural heterogeneity can facilitate the plastic deformation to be more homogeneous in space [19]. With regard to shear band dynamics, the morphology of shear bands confirms that the enhanced plasticity of MGs is a consequence of the serration dynamics behavior changes from chaotic to SOC state induced by increasing interaction and multiplication of shear bands. Based on the above understanding, it can be concluded that serrated flow behavior in MG is a structural heterogeneity-mediated process. The spatially structural heterogeneity is mainly through regulating the number and energy distribution of flow units in MGs to affect the activation, propagation, and interaction behavior of shear bands, in turn to mediate the spatiotemporal dynamics of serrated flow behavior, thereby to predetermine the plasticity of MGs. The obtained results might shed light on mechanism of plastic deformation and have some implications for develop new strategies to improve the plasticity of MGs.

\section{Conclusions}

In summary, Zr-based metallic glasses (MGs) with different degree of structural heterogeneities were fabricated under different cooling rates. The correlation between structural heterogeneity and serrated flow behavior were investigated. Based on our study the following conclusions can be drawn:

1. The relaxation enthalpy and frozen free volume of MGs increase with the fabrication cooling rate. It displays a good linear relationship with slope $\left(\beta^{\prime}\right)$ of about $540.6 \mathrm{~kJ} / \mathrm{mol} \cdot$ atom between the enthalpy and free volume. The MGs fabricated at higher cooling rate have a wider distribution of hardness than its counterparts with less.

2. The serration sizes display an increasing trend with rising strain for all samples, and the increasing rate of serration size $\left(\Delta \sigma_{\max }\right)$ $\Delta \varepsilon$ ) increases with decrease in structural heterogeneity. The $\Delta \sigma_{\max } / \Delta \varepsilon$ reflecting the likelihood of shear bands nucleation is determined by energy barrier distribution of flow units.

3. With increasing degree of structural heterogeneity, plastic deformation becomes more homogeneous in time and space. Statistical analyses reveal that serrated flow dynamics of MGs transforms from a chaotic state featured by Gaussian- 

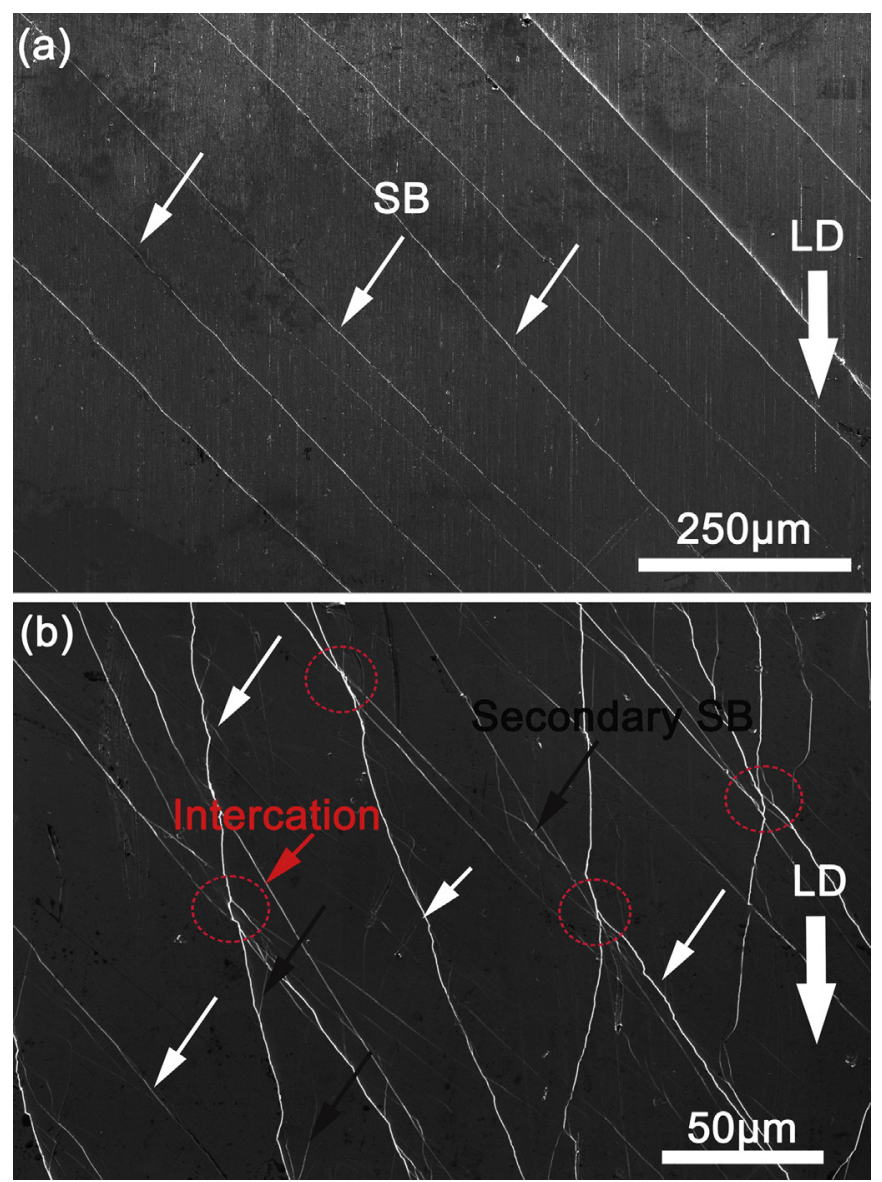

Fig. 8. SEM photographs of side surfaces for samples with different degree of structural heterogeneity: (a) Sample C, (b) Sample A, The black arrows indicate secondary shear band (SB), the red arrows are interactions of shear bands, "LD" denotes the loading direction. (For interpretation of the references to colour in this figure legend, the reader is referred to the Web version of this article.)

distribution of serrations into a self-organized critical state characterized by power-law distribution, corresponding to change of the randomly generated and uncorrelated shear bands to a collective motion of shear bands with a high tendency of forming shear band intersections.

\section{Acknowledgments}

P. J. Li gratefully acknowledges the financial support from the National Basic Research Program of China under contract No. 2013CB632203. Z. Y. Liu and Y. Lou would like to thank the financial support from Natural Science Foundation of China under contact No: 51601118 and No: 51675347. L.C. Zhang is grateful for the financial support by the Australian Research Council's Discovery Projects funding (DP130103592).

\section{References}

[1] Y. Zhang, J.P. Liu, S.Y. Chen, X. Xie, P.K. Liaw, K.A. Dahmen, Q.J. W, Y.L. Wang, Serration and noise behavior in materials, Prog. Mater. Sci. 90 (2017) $358-460$.

[2] M.A. Lebyodkin, Y. Brechet, Y. Estrin, L.P. Kubin, Statistics of the catastrophic slip events in the Portevin-Le Châtelier effect, Phys. Rev. Lett. 74 (1995) 4758.

[3] R. Carroll, C. Lee, C. Tsai, J. Yeh, J. Antonaglia, B.A. Brinkman, M. LeBlanc, X. Xie, S. Chen, P.K. Liaw, Experiments and model for serration statistics in lowentropy, medium-entropy, and high-entropy alloys, Sci. Rep. 5 (2015) 16997.

[4] B.A. Sun, S. Pauly, J. Tan, M. Stoica, W.H. Wang, U. Kühn, J. Eckert, Serrated flow and stick-slip deformation dynamics in the presence of shear-band interactions for a Zr-based metallic glass, Acta Mater. 60 (2012) 4160-4171.

[5] H.M. Chen, J.C. Huang, S.X. Song, T.G. Nieh, J.S.C. Jang, Flow serration and shear-band propagation in bulk metallic glasses, Appl. Phys. Lett. 94 (2009), 141914.

[6] W.A. Curtin, D.L. Olmsted, L.J. Hector, A predictive mechanism for dynamic strain ageing in aluminium-magnesium alloys, Nat. Mater. 5 (2006) 875-880.

[7] W.H. Wang, D. Wu, S.S.A. Shah, R.S. Chen, C.S. Lou, The mechanism of critica strain and serration type of the serrated flow in Mg-Nd-Zn alloy, Mater. Sci. Eng. A 649 (2016) 214-221.

[8] J.W. Qiao, H.L. Jia, P.K. Liaw, Metallic glass matrix composites, Mater. Sci. Eng R 100 (2016) 1-69.

[9] Z. Jia, X.G. Duan, P. Qin, W.C. Zhang, W.M. Wang, C. Yang, H.Q. Sun, S.B. Wang, L.C. Zhang, Disordered atomic packing structure of metallic glass: toward ultrafast hydroxyl radicals production rate and strong electron transfer ability in catalytic performance, Adv. Funct. Mater. 27 (2017), 1702258.

10] M.M. Trexler, N.N. Thadhani, Mechanical properties of bulk metallic glasses, Prog. Mater. Sci. 55 (2010) 759-839.

[11] R. Sarmah, G. Ananthakrishna, B.A. Sun, W.H. Wang, Hidden order in serrated flow of metallic glasses, Acta Mater. 59 (2011) 4482-4493.

[12] A. Vinogradov, A. Lazarev, D.V. Louzguine-Luzgin, Y. Yokoyama, S. Li, A.R. Yavari, A. Inoue, Propagation of shear bands in metallic glasses and transition from serrated to non-serrated plastic flow at low temperatures Acta Mater. 58 (2010) 6736-6743.

[13] G. Wang, K.C. Chan, L. Xia, P. Yu, J. Shen, W.H. Wang, Self-organized intermittent plastic flow in bulk metallic glasses, Acta Mater. 57 (2009) 6146-6155.

[14] X.L. Bian, G. Wang, K.C. Chan, J.L. Ren, Y.L. Gao, O.J. Zhai, Shear avalanches in metallic glasses under nanoindentation: deformation units and rate dependent strain burst cut-off, Appl. Phys. Lett. 103 (2013), 101907.

[15] W. Jiang, G. Fan, F. Liu, G. Wang, H. Choo, P. Liaw, Spatiotemporally inhomogeneous plastic flow of a bulk-metallic glass, Int. J. Plast. 24 (2008) 1-16.

[16] J.W. Qiao, Y. Zhang, P.K. Liaw, Serrated flow kinetics in a Zr-based bulk metallic glass, Intermetallics 18 (2010) 2057-2064.

[17] C. Wang B.A. Sun, W.H. Wang H.Y. Bai, Chaotic state to self-organized critica state transition of serrated flow dynamics during brittle-to-ductile transition in metallic glass, J. Appl. Phys. 119 (2016) 54902.

[18] K.K. Song, S. Pauly, B.A. Sun, J. Tan, M. Stoica, U. Kühn, J. Eckert, Correlation between the microstructures and the deformation mechanisms of $\mathrm{CuZr}$-based bulk metallic glass composites, AIP Adv. 3 (2013) 12116.

[19] W.H. Jiang, F. Jiang, F.X. Liu, H. Choo, P.K. Liaw, K.Q. Qiu, Temperature dependence of serrated flows in compression in a bulk-metallic glass, Appl Phys. Lett. 89 (2006) 261909.

[20] Z.F. Yao, J.C. Qiao, Y. Liu, J.M. Pelletier, Y. Yao, Aspect ratio effects on the serration dynamics of a Zr-based bulk metallic glass, J. Mater. Sci. 52 (2017) $138-144$

[21] Z.Y. Liu, G. Wang, K.C. Chan, J.L. Ren, Y.J. Huang, X.L. Bian, X.H. Xu, D.S. Zhang Y.L. Gao, Q.J. Zhai, Temperature dependent dynamics transition of intermittent plastic flow in a metallic glass. II. Dynamics analysis, J. Appl. Phys. 114 (2013) 33521

[22] W.H. Jiang, G.J. Fan, F.X. Liu, G.Y. Wang, H. Choo, P.K. Liaw, Rate dependence of shear banding and serrated flows in a bulk metallic glass, J. Mater. Res. 21 (2006) 2164-2167.

[23] S.H. Chen, K.C. Chan, G. Wang, F.F. Wu, L. Xia, J.L. Ren, J. Li, K.A. Dahmen, P.K. Liaw, Loading-rate-independent delay of catastrophic avalanches in a bulk metallic glass, Sci. Rep. 6 (2016) 21967.

[24] J. Hu, B.A. Sun, Y. Yang, C.T. Liu, S. Pauly, Y.X. Weng, J. Eckert, Intrinsic versus extrinsic effects on serrated flow of bulk metallic glasses, Intermetallics 66 (2015) 31-39.

[25] W.H. Wang, Y. Yang, T.G. Nieh, C.T. Liu, On the source of plastic flow in metallic glasses: concepts and models, Intermetallics 67 (2015) 81-86.

[26] J.C. Ye, J. Lu, C.T. Liu, Q. Wang, Y. Yang, Atomistic free-volume zones and inelastic deformation of metallic glasses, Nat. Mater. 9 (2010) 619-623.

[27] Y.H. Liu, D. Wang, K. Nakajima, W. Zhang, A. Hirata, T. Nishi, A. Inoue M.W. Chen, Characterization of nanoscale mechanical heterogeneity in a metallic glass by dynamic force microscopy, Phys. Rev. Lett. 106 (2011) 125504.

[28] H. Wagner, D. Bedorf, S. Küchemann, M. Schwabe, B. Zhang, W. Arnold K. Samwer, Local elastic properties of a metallic glass, Nat. Mater. 10 (2011) 439-442.

[29] F. Zhu, H.K. Nguyen, S.X. Song, D.P. Aji, A. Hirata, H. Wang, K. Nakajima, M.W. Chen, Intrinsic correlation between $\beta$-relaxation and spatial heterogeneity in a metallic glass, Nat. Commun. 7 (2016) 11516.

[30] B. Huang, H.Y. Bai, P. Wen, D.W. Ding, D.Q. Zhao, M.X. Pan, W.H. Wang, The heterogeneous structure of metallic glasses revealed by superconducting transitions, J. Appl. Phys. 114 (2013), 113508.

31] S.V. Ketov, Y.H. Sun, S. Nachum, Z. Lu, A. Checchi, A.R. Beraldin, H.Y. Bai W.H. Wang, D.V. Louzguine-Luzgin, M.A. Carpenter, A.L. Greer, Rejuvenation of metallic glasses by non-affine thermal strain, Nature 524 (2015) 200-203.

32] Z. Wang, B.A. Sun, H.Y. Bai, W.H. Wang Evolution of hidden localized flow during glass-to-liquid transition in metallic glass, Nat. Commun. 5 (2014) 5823.

[33] Z. Lu, W. Jiao, W. H. Wang, H.Y. Bai, Flow unit perspective on room temperature homogeneous plastic deformation in metallic glasses, Phys. Rev. Lett. 113 (2014), 045501.

[34] H.B. Yu, W.H. Wang, H.Y. Bai, K. Samwer, The $\beta$-relaxation in metallic glasses, 
Natl. Sci. Rev. 1 (2014) 429-461.

[35] Z.Y. Liu, Y. Yang, C.T. Liu, Yielding and shear banding of metallic glasses, Acta Mater. 61 (2013) 5928-5936.

[36] Z.Y. Liu, M.W. Chen, C.T. Liu, Y. Yang, Origin of yielding in metallic glass: stress-induced flow, Appl. Phys. Lett. 104 (2014), 251901.

[37] A. Gulzar, L.Z. Zhao, R.J. Xue, K. Shahzad, D.Q. Zhao, W.H. Wang, Correlation between flow units and crystallization in metallic glasses, J. Non-Cryst. Solids 461 (2017) 61-66.

[38] T.P. Ge, X.Q. Gao, B. Huang, W.H. Wang, H.Y. Bai, The role of time in activation of flow units in metallic glasses, Intermetallics 67 (2015) 47-51.

[39] R.J. Xue, D.P. Wang, Z.G. Zhu, D.W. Ding, B. Zhang, W.H. Wang, Characterization of flow units in metallic glass through density variation, J. Appl. Phys. 114 (2013), 123514.

[40] Z. Zhu, E. Ma, J. Xu, Elevating the fracture toughness of $\mathrm{Cu}_{49} \mathrm{Hf}_{42} \mathrm{Al}_{9}$ bulk metallic glass: effects of cooling rate and frozen-in excess volume, Intermetallics 46 (2014) 164-172.

[41] K. Vollmayr, W. Kob, K. Binder, How do the properties of a glass depend on the cooling rate? A computer simulation study of a Lennard-Jones system, J. Chem. Phys. 105 (1996) 4714-4728.

[42] M. Wakeda, J. Saida, J. Li, S. Ogata, Controlled rejuvenation of amorphous metals with thermal processing, Sci. Rep. 5 (2015) 10545.

[43] A. Slipenyuk, J. Eckert, Correlation between enthalpy change and free volume reduction during structural relaxation of $\mathrm{Zr}_{55} \mathrm{Cu}_{30} \mathrm{Al}_{10} \mathrm{Ni}_{5}$ metallic glass, Scr. Mater. 50 (2004) 39-44.

[44] A. Concustell, F.O. Méar, S. Suriñach, M.D. Baró, A.L. Greer, Structural relaxation and rejuvenation in a metallic glass induced by shot-peening, Phil. Mag. Lett. 89 (2009) 831-840.

[45] D.J. Magagnosc, G. Kumar, J. Schroers, P. Felfer, J.M. Cairney, D.S. Gianola, Effect of ion irradiation on tensile ductility, strength and fictive temperature in metallic glass nanowires, Acta Mater. 74 (2014) 165-182.

[46] X.L. Bian, G. Wang, H.C. Chen, L. Yan, J.G. Wang, Q. Wang, P.F. Hu, J.L. Ren, K.C. Chan, N. Zheng, A. Teresiak, Y.L. Gao, Q.J. Zhai, J. Eckert, J. Beadsworth, K.A. Dahmen, P.K. Liaw, Manipulation of free volumes in a metallic glass through Xe-ion irradiation, Acta Mater. 106 (2016) 66-77.

[47] J.G. Wang, D.Q. Zhao, M.X. Pan, C.H. Shek, W.H. Wang, Mechanical heterogeneity and mechanism of plasticity in metallic glasses, Appl. Phys. Lett. 94 (2009) 31904

[48] M. Song, Y.Y. Sun, Y.H. He, S.F. Guo, Structure related hardness and elastic modulus of bulk metallic glass, J. Appl. Phys. 111 (2012) 53518.

[49] W.H. Wang, Correlation between relaxations and plastic deformation, and elastic model of flow in metallic glasses and glass-forming liquids, J. Appl. Phys. 110 (2011) 53521.

[50] Z. Wang, P. Wen, L.S. Huo, H.Y. Bai, W.H. Wang, Signature of viscous flow units in apparent elastic regime of metallic glasses, Appl. Phys. Lett. 101 (2012) 121906.

[51] H.L. Peng, M.Z. Li, B.A. Sun, W.H. Wang, Characterization of mechanical heterogeneity in amorphous solids, J. Appl. Phys. 112 (2012) 23516.

[52] G.N. Yang, S.Q Chen, J.L. Gu, S.F. Zhao, J.F. Li, Y. Shao, H. Wang, K.F. Yao, Serration behaviours in metallic glasses with different plasticity, Phil. Mag. 96 (2016) 2243-2255

[53] J.W. Qiao, Z. Wang, Z.M. Jiao, H.J. Yang, S.G. Ma, Z.H. Wang, B.S. Xu, Predicting burst sizes in amorphous alloys during plastic flows, Mater. Sci. Eng. A 609 (2014) 222-225.

[54] B.A. Sun, H.B. Yu, W. Jiao, H.Y. Bai, D.Q. Zhao, W.H. Wang, Plasticity of ductile metallic glasses: a self-organized critical state, Phys. Rev. Lett. 105 (2010) 35501.

[55] G. Ananthakrishna, S.J. Noronha, C. Fressengeas, L.P. Kubin, Crossover from chaotic to self-organized critical dynamics in jerky flow of single crystals, Phys. Rev. E 60 (1999) 5455.

[56] M.B. Harris, L.S. Watts, E.R. Homer, Competition between shear band nucleation and propagation across rate-dependent flow transitions in a model metallic glass, Acta Mater. 111 (2016) 273-282.

[57] S.T. Liu, Z. Wang, H.L. Peng, H.B. Yu, W.H. Wang, The activation energy and volume of flow units of metallic glasses, Scr. Mater. 67 (2012) 9-12.

[58] K. Fujita, A. Inoue, T. Zhang, N. Nishiyama, Anelastic behavior under tensile and shearing stresses in bulk metallic glasses, Mater. Trans. 43 (2002) 1957-1960.

[59] Y. Zhang, A.L. Greer, Thickness of shear bands in metallic glasses, Appl. Phys. Lett. 89 (2006) 71907.

[60] S.X. Song, T.G. Nieh, Flow serration and shear-band viscosity during inhomogeneous deformation of a Zr-based bulk metallic glass, Intermetallics 17 (2009) 762-767.

[61] W.J. Wright, R. Saha, W.D. Nix, Deformation mechanisms of the $\mathrm{Zr}_{40} \mathrm{Ti}_{14} \mathrm{Ni}_{10}$ $\mathrm{Cu}_{12} \mathrm{Be}_{24}$ bulk metallic glass, Mater. Trans. 42 (2001) 642-649.

[62] D.L. McDowell, Viscoplasticity of heterogeneous metallic materials, Mater. Sci. Eng. R 62 (2008) 67-123.

[63] L.H. Liu, C. Yang, F. Wang, S.G. Qu, X.Q. Li, W.W. Zhang, Y.Y. Li, L.C. Zhang, Ultrafine grained Ti-based composites with ultrahigh strength and ductility achieved by equiaxing microstructure, Mater. Des. 79 (2015) 1-5.

[64] B.A. Sun, Y. Yang, W.H. Wang, C.T. Liu, The critical criterion on runaway shear banding in metallic glasses, Sci. Rep. 6 (2016) 21388.

[65] L.H. Liu, C. Yang, Y.G. Yao, F. Wang, W.W. Zhang, Y. Long, Y.Y. Li, Densification mechanism of Ti-based metallic glass powders during spark plasma sintering process, Intermetallics 66 (2015) 1-7.

[66] B.A. Sun, S. Pauly, J. Hu, W.H. Wang, U. Kühn, J. Eckert, Origin of intermittent plastic flow and instability of shear band sliding in bulk metallic glasses, Phys. Rev. Lett. 110 (2013), 225501.

[67] R.T. Qu, Z.Q. Liu, G. Wang, Z.F. Zhang, Progressive shear band propagation in metallic glasses under compression, Acta Mater. 91 (2015) 19-33.

[68] W. Jiao, P. Wen, H.L. Peng, H.Y. Bai, B.A. Sun, W.H. Wang, Evolution of structural and dynamic heterogeneities and activation energy distribution of deformation units in metallic glass, Appl. Phys. Lett. 102 (2013), 101903. 